\title{
The Potential of Common Beneficial Insects and Strategies for Maintaining Them in Bean Fields of Sub Saharan Africa
}

\author{
Baltazar Ndakidemi, Kelvin Mtei, Patrick A. Ndakidemi \\ Department of Water and Environmental Sciences (WESE), The Nelson Mandela African Institution of Science \\ and Technology, Arusha, Tanzania \\ Email:ndakidemib@nm-aist.ac.tz
}

Received 4 January 2016; accepted 5 March 2016; published 10 March 2016

Copyright (C) 2016 by authors and Scientific Research Publishing Inc.

This work is licensed under the Creative Commons Attribution International License (CC BY). http://creativecommons.org/licenses/by/4.0/

c) (i) Open Access

\begin{abstract}
Beneficial insects provide natural ecosystem services such as biological control of pests, soil formation, nutrient cycling and pollination of plants. Beneficial insects include pollinators important in the essential pollination process of all plants, and natural enemies of pests such as parasitoids and predators which are important in the suppression of pest damage to crops. Knowledge on management techniques to attract beneficial insects in the agricultural fields is a way forward to enhance agro ecosystems for increased crop production. Therefore, proper understanding and identification of natural enemies, as well as pollinators in agricultural fields, is essential in promoting biological control and pollination activity. Natural enemies and pollinators, within legume fields, play a key role in ensuring sustainable production, especially in smallholder farms. There is a limited understanding of beneficial insects and the ecosystem services they offer to the agricultural production process in much of sub-Saharan Africa. This paper reviewed and provided existing knowledge on beneficial insects in bean fields. This will give the basis for research on beneficial insects in bean fields and practices that encourage their populations.
\end{abstract}

\section{Keywords}

Ecosystem Services, Biological Control, Natural Enemies, Pollinators, Pest Management

\section{Introduction}

The Millennium Ecosystem Assessment categorizes ecosystem services into four groups, which are provisioning services (timber, medicinal plants, and fish); regulating services (climate control, pollutants removal, disasters 
protection); cultural services (spiritual value from sacred groves, aesthetic beauty) and supporting services (soils formation, nutrient recycling, natural pest control and pollination) [1]. Beneficial insects which mainly include natural enemies and pollinators provide ecosystem services such as pollination and pest-diseases management. These services are essential in plants' life and enhancement of crop productivity.

To map the temporal and spatial provision of ecosystem services, the knowledge of ecosystem and biodiversity is potential for sustainable ecosystem services and avoiding the disservices from agricultural fields [2]. Valuation of the ecosystem services is the step forward towards ensuring ecosystem services sustainability [3].

In integrated pest management (IPM) strategy, natural enemies can be employed together with other methods such as chemical, cultural, genetic methods for maximum control. For chemical control methods, selective insecticides can be employed with fewer effects to natural enemies. Landscape manipulation will also enhance biological control in agricultural fields [4].

Natural enemies are a diverse group of organisms that include predators, parasitic insects, nematodes and microorganisms. Predators, which are often large, active and conspicuous in their behaviour, consume many insect preys in their lifetime [5]. Common predators of insect pests include praying mantis, spiders, earwigs, true bugs, ladybird beetles, ground beetles, lacewings, and hoverfly larvae [6]. Parasites of insects (parasitoids) are insects which develop within their pest hosts [5]. The parasitic mechanism is by laying eggs in or on the body of another insect and when the parasite egg hatches the young parasite larva feeds on the host insect (pest) and kills it. These are mostly wasps or flies of small sizes and most of them are host specific [7]. Parasitic insects are therefore parasitic only in their immature (larvae) stage. While the immature parasitoid kills only one host during its development, each individual predator kills many preys.

The predatory beetles are the most diverse group of insects in the world constituting of about $40 \%$ of all known insects species in the world [8]. Beetles in the order Coleoptera consist of different families but of importance in crop protection are family Carabidae (ground beetles) and family Coccinelidae (lady beetles). Lady beetles are the important group of natural enemies [8]. Praying mantis (mantodae) are generalists that attack most pests, natural enemies and each other. Nymphs and adults are both predatory [9]. Predatory bugs (true bugs) of the order Hemiptera include damsel bugs, big-eyed bugs, minute pirate bugs, mirid bugs, stink bugs, assassin bugs and ambush bug. Both adults and nymphs are predators. These are all generalist feeders and may eat some beneficial insects. Green bugs feed on plants and brown feed on insects [10]. Lacewings in the order Neuroptera present many favourable traits such as wide prey range and high voracity [11]. Predatory flies of the order Diptera include hover flies, dance flies, long-legged flies, robber flies and tachinid flies. Stinging wasps of the two major families of Vespidae and Sphecidae include paper wasps, yellow jackets, and hunting wasps. Most of these wasps construct a cell or a nest in which they lay eggs. Some dig a tunnel in the soil [10]. Spiders of the families Salticidae, Thomisidae, Oxyopidae, and Araneidae will target a large range of flying and crawling insects. Green tree ant Oecophylla smaragdina (Family Formicidae) and Red meat ant Iridomyrmex sanguineus (Family Formicidae) will target a large range of slow moving insects such as caterpillars, beetles and others [12].

Natural enemies as the agents of biological control regulate pest numbers in many circumstances [13]. They can directly cause pest mortality and can indirectly interfere with the feeding activities of pest species and therefore, reduce damage to crops [14].

Most of the natural enemies play a secondary role in pollinating food crops and flowering plants. Key pollinators include bees (honey bees and wild bees), butterflies, moths and flies [15].

These natural enemies and pollinators within the environment, especially in the agricultural fields, play key roles in ensuring sustainable production. Legumes, being one of the important crops cultivated by smallholder farmers for food security and nutrition quality especially in the sub-Saharan Africa, are among the beneficiary of these insects. There is, however, a limited understanding of beneficial insects and the ecosystem services they offer to agricultural production process including bean farms in much of sub-Saharan Africa. To ensure sustainability in such production systems, there is a need to identify and promote management of these beneficial insects. This review aims at exploring the existing knowledge and information on beneficial insects in bean fields which will provide basis for further investigation and recommend adequate management practices.

\section{Natural Enemies in Bean Fields}

Some natural enemies of pests in common beans have been studied. They include parasitic wasps, ground 
beetles, lady beetles, hover flies, lacewings, predatory bugs (assassin bugs), ants, spiders, predatory and parasitic flies [16].

\subsection{Assassin Bug (Hemiptera: Reduviidae)}

The assassin bug is large compared with other predatory bugs. Most range in colour from light brownish-green to dark-brown. The species is known as "Assassin bug" or "the masked bed bug hunter" [17]. The front legs are enlarged for grasping prey. They often live more than one season and consume large numbers of small insects and mites. The adult female lays cylindrical brown eggs in clusters. Some representative members of this family include thread-legged bugs, ambush bugs and the wheel bug. Both nymph (Figure 1) and adults are predatory of most insects [18]. They have been reported to prefer most crops which include legumes (e.g. peanut, soybean, sesame, lucerne, mung bean) cocoa, rice, mango, hibiscus and melaleuca [12].

Assassin bugs are generalist predators that may feed on leafhoppers, plant bugs, caterpillars and their eggs and larvae [5]. They ambush their prey which capture and pierce with their strong rostrum. Salivary secretion paralyses the prey and dissolves its internal tissues into a liquid which is sucked up by the bug [12]. Greater understanding of their potential prey and the environments that are more favourable for assassin bugs may contribute significantly in promoting their populations in the bean fields.

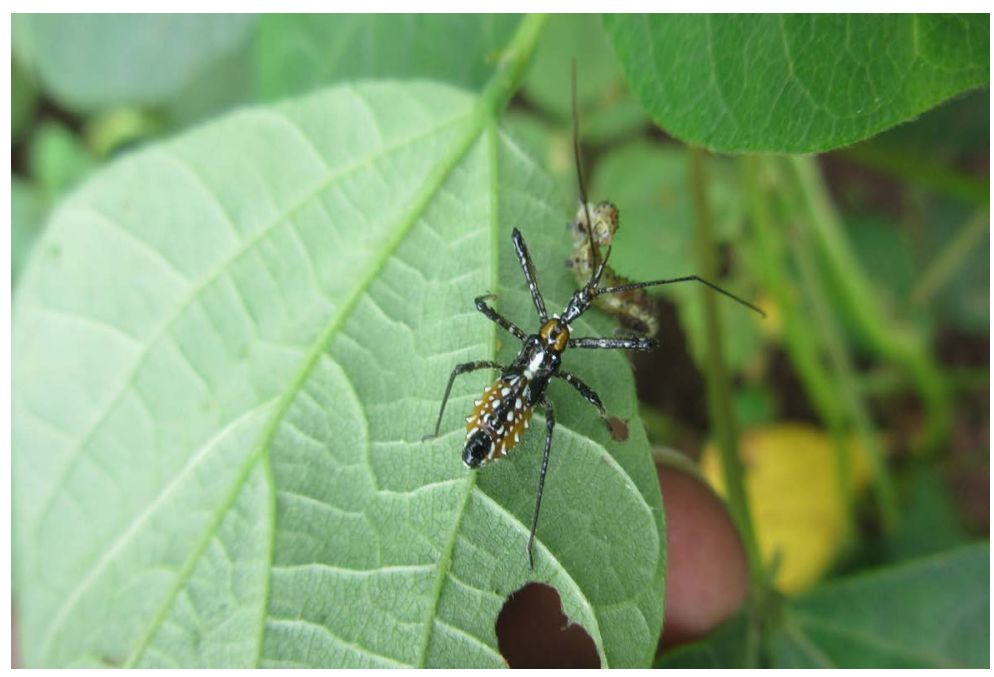

Figure 1. Field picture of assassin bug nymph.

\subsection{Hoverflies (Diptera: Syrphidae)}

Hoverflies (Figure 2) are also known as flower flies because of their behaviour of frequently visiting flowers and feed on nectar and pollen making them good pollinators. They resemble wasps, with their yellow or orange and black banded abdomens but hoverflies excel in the behavior of hovering which is not the case of wasps. Eggs are usually deposited on or near the host insect and develop to adult in 2 to 6 weeks [5]. The body of the larva tapers towards the head and are generally white, brownish or green in colour. Adults are stout or slender-bodied with a large head and eyes. Some species of hoverfly larvae live in rotting vegetation while some larvae are aquatic such as the rat-tailed maggots. The adults are often seen in flowers while larvae live in stagnant, polluted water. Plants which attract the adult hoverflies include Queen Anne's lace, dill, fennel, caraway, tansy, parsley, coriander, bishop's weed, coreopsis, gloriosa daisy, yarrow, cosmos, sunflower, marigolds, candytuft, sweet alyssum, ceanothus, holly, leaved cherry, buckwheat, scabiosa, spearmint, coyote brush, knotweed, California lilacs, soapbark tree, meadow foam, baby-blue-eyes. Also, they prefer decaying vegetation [19].

The hoverfly larvae feed voraciously on aphids, thrips, mites, and other small insects. The larvae are predatory and the adults are pollinators and require nectar and pollen for survival and therefore, they normally hover on flowers [18]. More studies are needed to determine the management practices in bean fields that will support hoverflies, their predatory and pollination activities. Their presence at the right times in the field and at reasonable proximity to the farm is essential for effective pollination and pest control services. 


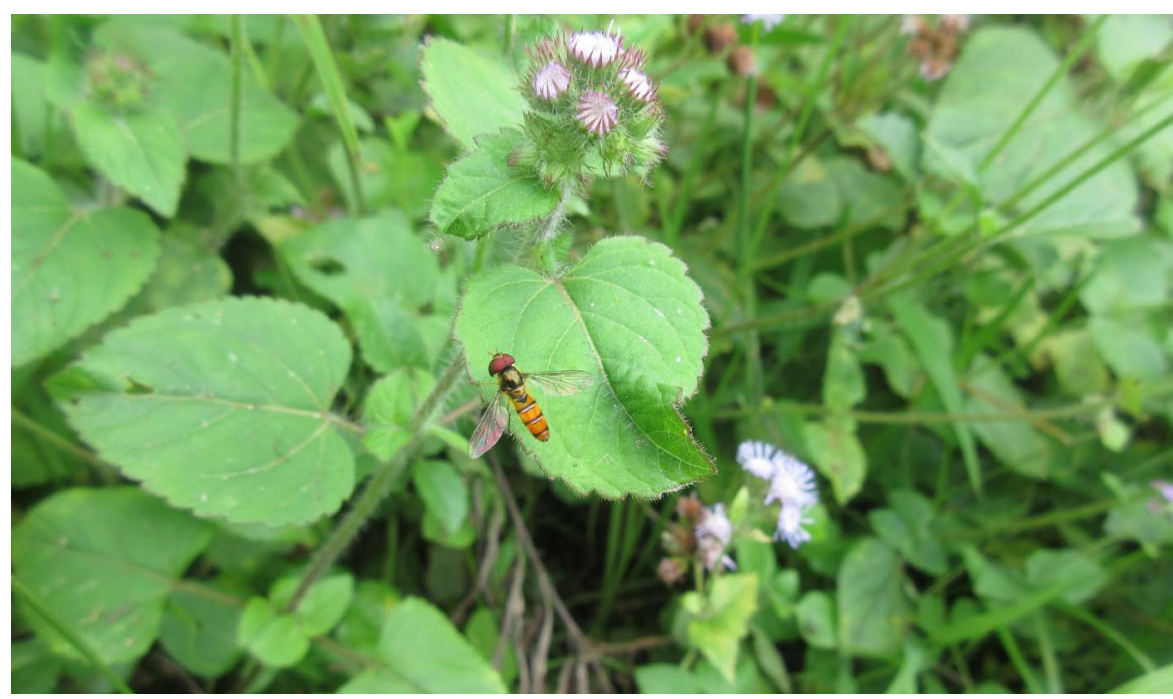

Figure 2. Field picture of adult hoverfly.

\subsection{Ground Beetles (Coleoptera: Carabidae)}

Ground beetles (Carabids) are ground-dwelling [20]. They live in soil and detritus, though some, particularly the Lebia species and some caterpillar hunters forage in the plant canopy. They tend to be more active at night and hide under crop debris and in cracks in the soil during the day. Ground beetles need undisturbed areas to overwinter. If disrupted by insecticides, their populations are slow to rebound as they have long life cycles. Carabids are largely nocturnal. They are usually brown or black, but a few are metallic blue or green. Permanent plantings, amaranth, white clover and mulch will attract the Carabids. They live in arable crops and heavier soils, trees and shrubs. Most of them climb into vegetation at night [8]. Adults and larvae are predatory. Beetles of the genus Calosoma are known as caterpillar hunters because they are voracious predators of caterpillars. Adults and larvae of most species are predators of cutworms, ants, maggots, earthworms, slugs, and other beetles. Most of the species are generalists [12]. Knowledge of predatory activities of the Carabids and their requirements at different life stages is important in increasing their efficiency in control of pests in bean fields and therefore increase the bean yields. As the Carabids are ground-dwellers, reducing tillage would be one of the ways to conserve them. Higher soil temperatures also may destroy the ground beetles therefore, incorporating the cover crops or mulches would reduce the temperatures.

\subsection{Lady Beetles (Coleoptera: Coccinellidae)}

There are several species of lady beetles, but the important ones are the transverse, convergent, seven-spot, multi-coloured, and mite-eating lady beetles [21]. Lady beetles (Figure 3) are predators and are very important in the suppression of pests and therefore, should be attracted and conserved for more effective and sustainable way of pests' management. Both the adult and larval stages of lady beetles are predators. The larvae of the lady beetles look like a very small alligator. They undergo complete metamorphosis. The larvae are sometimes described as "alligator shaped" and are soft bodied and elongate. Development from egg to adult takes 30 to 40 days. Most species tend to specialize feeding on aphids. They are thought to be oval and the colouration varies from pink to red to orange to black. The number and patterns of spots also vary. They are attracted by plant pollen and nectar producing plants which include Caraway, dill, parsley, fennel, Queen Anne's, white lace clover, angelica, goldenrod, mustard, tansy, yarrow, sunflower, hairy vetch, buckwheat, cowpea, common, native grasses, knotweed, crocuses, spearmint, grains, buckthorn, black locust and salt bush [22]. They also need floral resources such as plant pollen and nectar resources as well for their survival for instance, the spotted lady beetles need pollen (spring beauty, dandelion) after overwintering [5] [20].

Although most species are generalists, adults and larva of lady beetles destroy the aphids, mites, thrips, scale insects, mealy bugs, and insect eggs overwintering [5]. Information on supplemental food resources for ladybugs is the way forward towards promoting their populations and extend their predatory and pollination activities. 


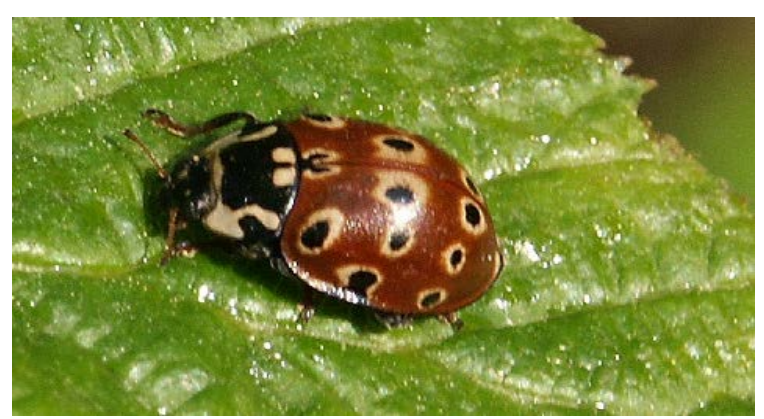

Figure 3. Adult lady beetle (Source [19]).

\subsection{Brown Lacewing (Neuroptera: Hemerobiidae) and Green Lacewing (Neuroptera: Chrysopidae)}

Lacewings have long antenna and golden eyes and are more active in warm weather. Brown lacewings are larger but less common than Green lacewings. The eggs of Green lacewings are laid singly or in batches, each on a long, hair-like stalk, presumably to keep the egg away from substrate-based predators and also to reduce the chances of cannibalism among the larvae known as aphid lions [11]. Both the larvae and adults brown lacewings are predatory [22]. Development from egg to adult takes to about 25 days and adults live for about 30 days. The adult lacewings are delicate, slender-bodied. The larvae of green lacewing which have pincer-like mouthparts are parasitic. They prefer tree and shrub crops and flowering crops and vegetation nearby will encourage adults to stay as they feed on nectar and pollen. Many species of lacewings are found naturally in orchards. Plants that attract and conserve Lacewing are the Carrot family, sunflower family, buckwheat, holly leaf cherry, corn [5].

Lacewing larvae prey on insect eggs, leafhoppers, mites, red-banded thrips, mites, immature mealy bugs, moth eggs and small caterpillars. Adult Green lacewings are not predaceous while adult brown lacewings are. Larvae have large piercing mandibles for capturing prey. Green lacewing adults feed on nectar and pollen [22]. There is limited knowledge of the variations of lacewing populations in relation to the environmental factors such as rainfall and temperature. Exploring these variations will help in conserving the lacewings.

\subsection{Long-Legged Flies (Diptera: Dolichopodidae)}

Long-legged flies are metallic green to blue with distinctive long legs preferring moist areas, especially in gardens (Figure 4). Generally, they are metallic green in colour, but they can also be yellow, brown or black. The development of the larvae takes place in the soil, on dead organic matter or in tree crevices. Field margins and crops attract the adults. They are strong flyers [23].

Both the larvae and the adults are predators. They prey on aphids, thrips, young caterpillars, and mites. They are also likely to be predators or scavengers in detritus and soil [8]. Dolichopodidae plays a potential role in pest regulation. Little is known on the long-legged flies and their roles in agricultural fields especially in bean fields. There is a need of generating more information on the long-legged flies and the role (s) they play in control of pests to promote the control of pests in bean field.

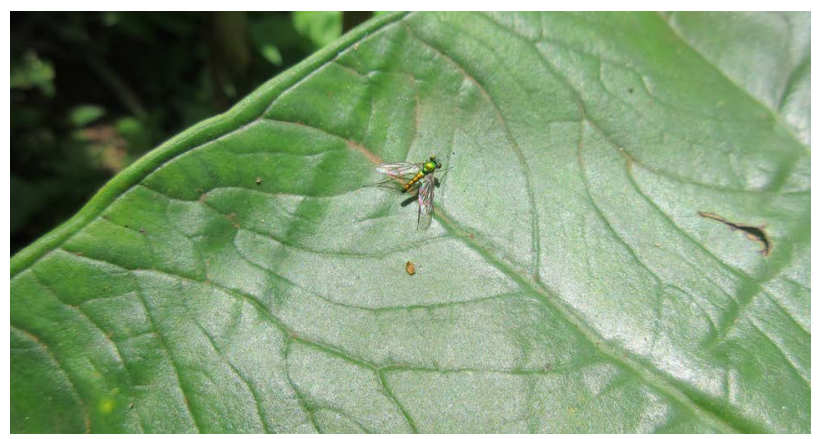

Figure 4. Field picture of adult long-legged fly. 


\subsection{Robber Flies (Diptera: Asilidae)}

Robber flies are large (Figure 5). The larvae are cylindrical, elongate and tapered at each end and have a small distinct head. They are commonly found in soil or rotting wood. The eggs are laid in the soil or attached to foliage, bark or in the seed heads of grasses. Suitable crops or vegetation for Robber flies is native vegetation, permanent hedgerow as well as various crops [12].

Robber flies are predators which capture prey while in flight because of their prominent eyes, long legs and tapered slender abdomen. They use their proboscis to inject toxins and enzymes into the body of the prey. This dissolves the contents which will be sucked out. They consume a wide range of insects including flies, wasps, grasshoppers, leafhoppers, beetles, and butterflies. Robber fly larvae live in the soil and feed on small insects [8]. There is a need of studying the dynamics of the predatory activities of the robber flies in biological control systems. This is crucial for pest control in bean fields.

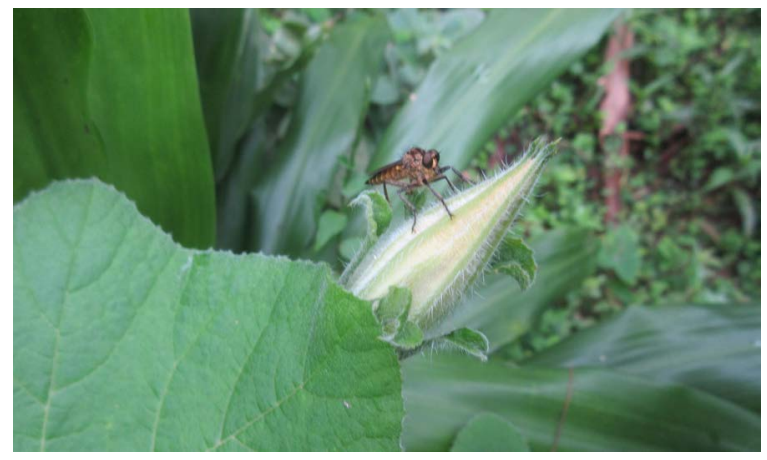

Figure 5. Field picture of adult robber fly.

\subsection{Tachinid Flies (Diptera: Tachinidae)}

Tachinid fly (Tachinidae family) resemble houseflies but are bigger. Tachinids are usually dark gray or striped, robust, and hairy, with stout bristles at the tip of their abdomen. Small eggs are usually deposited on, or near the host insects. The larvae are endoparasite of insects. The complete life cycle takes about 4 weeks. Adult tachinid flies feed on pollen and nectar and they prefer various crops and situations independent of crop type. They are found wherever hosts are found [9].

Young larvae of tachinid flies bore their way into their caterpillar hosts and feed on internal organs until the host dies and the larva reemerges to pupate. Most tachinid fly larvae or maggots parasitize the host insects from within. The larvae parasitize green clover worm, bean leaf beetle, beetle larvae, grasshoppers and caterpillars [24]. Judicious pesticide use will help in conservation process [5]. These large parasitoids vary in their preferred host, so it is important to establish the alternative prey/host for tachinid flies at some points of their life cycles. More studies are needed on alternative prey/hosts for tachinid flies and environmentally benign practices that support them.

\subsection{Spiders (Araneae)}

Spiders are generalist predators providing an enormous pest control service. They occupy a variety of habitats with correspondingly different behaviors and prey preferences. They are found in the soil, low vegetation or woody plants. Adult spiders have silk-producing organs with neither antennae nor wings. The eggs are in silken sacs, protected by the female. Diversity of spiders is more in undisturbed natural environments than in agricultural settings. They prefer less disturbed perennial crops (forests, orchards, vineyards) than annual crops [19]. Spiders feed on a wide range of insects which include red-banded thrips, plant hoppers, caterpillars and moths. Crab spiders (Figure 6), for instance, secure their prey by ambush and stealth. Camouflaged, they lie in wait for prey. Some species slowly change colour to match their flower perch. They also stalk their prey on the ground. Thus, each spider species will catch certain prey type based on its method of prey capture and preferred habitat. They have usually one generation per year [10]. Spiders have prey and habitats preferences. Better understanding their habitats and their prey therefore will promote their populations in agricultural fields such as bean fields. 


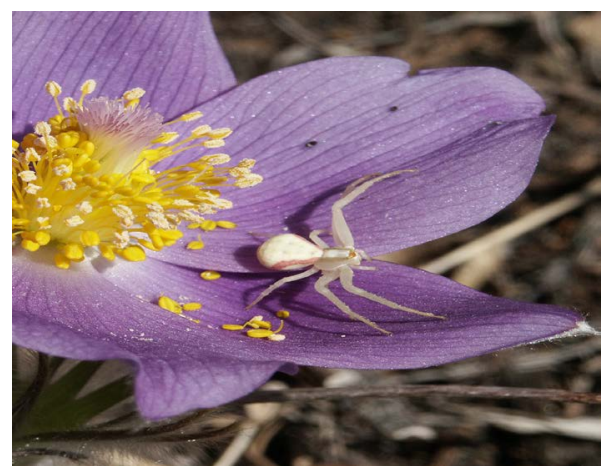

Figure 6. Crab spider (Source [19]).

\subsection{Trichogramma Wasps (Hymenoptera: Trichogrammatidae)}

These are tiny wasp parasites. They appear like moving dots or dust [25]. Parasitized eggs of the hosts, turns black in colour and, therefore, it is relatively easy to detect the presence of adults as they are too small to be seen in the fields [26].

Trichogramma wasps attack eggs of other insects by injecting eggs into them. They are important parasites of butterflies and moths. These wasps parasitize the eggs of armyworms, corn earworms, cutworms, European corn borers, Encarsia formosa, Orius sp., Geocoris sp., and Doruluteipes [27]. Their larvae develop inside the hosts, consume the contents and pupate. Mature adults will exit the eggs and eventually seek a suitable host egg [15]. Trichogrammatoidea eldanae, is potential in the control of bean pod borer Maruca vitrata [13].

These tiny parasitoids are very potential in control of bean pest particularly the bean pod borer Maruca vitrata. Further research on their parasitic activities and the favourable environments is the way forward towards preserving them hence, promoting biological control in bean fields.

\section{Pollinators}

Most of the predators and parasitoids feed on nectar or pollen and in so doing they play a secondary beneficial role of pollinating the flowers. These parasitoids and predators which display this double-role include hover flies, predatory bugs, lady beetles, lacewings, predatory wasps, and predatory flies. The honey bees, is the most important group of pollinators. Wild bees, butterflies and moths (order Lepidoptera) also play a great role in pollination and they are mostly attracted in the field by coneflower, columbine, asters and blazing star [15]. Pollinators face many challenges in the modern world. Habitat loss, disease, parasites, and environmental contaminants have all contributed to the decline of many species of pollinators [28]. Additional floral resources are sometimes needed by pollinators as their life cycles are longer than the flowering periods of the targeted plant crops [29]. Therefore, more research is needed on the dynamics of the pollinator populations in relation to their habitats and their supplemental food sources.

\subsection{Honey Bees (Hymenoptera: Apidae)}

Honey bees (Figure 7) are commonly kept in domestic beehives or found in and live in wild while in large colonies. They nest underground, in twigs and debris, or in dead trees [30]. Adult honey bees look like hoverflies. They pollinate a number of herbs, wildflowers, trees and many crops through feeding on nectar and pollen. Bees spend their adult lives gathering, transporting and feeding their immature offspring and this makes them be excellent pollinators [31]. Pollination activities of the honey bees are enhanced by fixing the hives to fields hence increased abundance and management [32]. They produce honey from nectar. For just a teaspoonful of honey, honey bees use four workers in their entire lives. Some useful products are produced by honey bees. These are royal jelly, propolis and beeswax [33]. Most of the pesticides particularly carbaryl and fipronil affect bees. Cooler weather is preferable for the bees to forage in the flower especially in the early morning [12].

Honey bees are important pollinators of Fabaceae crop species. Use of chemical pesticides will destroy them. Thus, good knowledge on the ways to conserve the honey bees is important in enhancing their pollination activity. The use of botanical pesticides for instance, would help in conserving the honey bees and therefore increase their beneficial role of pollinating the crops especially of the Fabaceae family. 


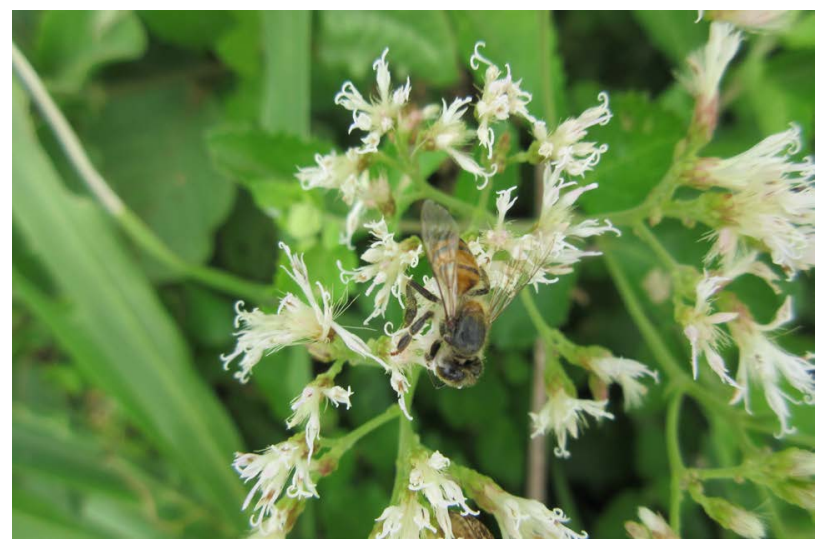

Figure 7. Field picture of the European honey bee.

\subsection{Butterflies (Lepidoptera: Rhopalocera) and Moths (Lepidoptera: Psychidae)}

Butterflies and moths are pollinators. Their larvae are caterpillars and sometimes caterpillars behave as pests. The presence of scales on the external parts of the body, particularly the wings makes them different from other insects. Male and female butterflies attract each other by sight while moths attract each other by scent [23]. Butterflies have immense appeal. Red flowers with short tubes are preferred by butterflies while white or pale with strong fragrance are preferred by moths. Most of the moths are day-flying, but the nectar-feeding moths are nocturnal. Nectar-feeding butterflies are day-flying [31].

Butterflies and moths are pollinators, and are an ideal flagship species for conservation. But their larvae are often pests. Further research on the biology of these insects at different stages of their life cycles would help in improving their pollination activities in Fabaceae crop species.

\section{Strategies for Maintaining Beneficial Insects in Bean Fields}

\subsection{Establishing Mixed Cultures}

[34] reported that, the diversification of agricultural fields by practicing mixed cropping farming that allows more different crop varieties or species within the same field, will enhance beneficial insect diversity and discourage pests. This is because when a herbivore finds no plant to feed on, it will spend more time and energy searching for food and, therefore, this will reduce the extent of damage the pest causes to the plant and in some cases encourages migration to another area in search of a suitable food source. [35] reported the decrease in insect pest populations' when beans were intercropped with maize in diversified cropping systems. Intercropping with insectary plants can be used to enhance the activity of predators and parasitoids by providing habitat and necessary floral resources.

Intercropping snap beans with African marigold (Tagetes erecta) and Coriander (Coriandrum sativum) reduced the populations of flower thrips. Intercropping will attract or repels pests from the crop and promote populations of natural enemies [36]. Investigations of different mixed cropping systems in bean fields could enhance the abundance, host-finding and pollination efficiency.

\subsection{Habitat Manipulation}

Manipulation of the field margin by maintaining vegetation with sufficient foliage in bean fields which provide nesting sites, restoration of native plants in the adjacent natural areas will enhance the diversity of beneficial arthropods in the edges of the main crop [37]. For instance, most wasps construct a cell or a nest which they lay eggs. Encouraging the number of nest locations for wasps in the bean fields, for instance, will help in maintaining more colonies to develop in the area and hence bean crops will benefit from biological control and pollination activities [10]. A field with a good diversity of local, native flora will attract a good diversity of local, beneficial arthropods and also will provide natural overwintering sites and flowering resources for many beneficial insects [38] [39].

[40] reported that there was a positive correlation between the proportions of non-crop habitat in the sur- 
rounding landscape and the spider density. [41] reported that the forest with a number of wild bees could provide pollination services that were of greater value to the nearby coffee field compared to the services the forest could provide for the forested land itself. Few studies have demonstrated the importance of habitat management practices and the ways beneficial insects benefit from the practices. It is therefore, important to demonstrate and establish how the manipulation practices in bean fields may influence the abundance and efficiency of beneficial insects.

\subsection{Incorporating Cover Crops}

Cover crops have been reported to enhance populations of beneficial insects especially for biological control of insect pests [10]. Some best nectar source plants are sometimes incorporated in bean fields. Examples are wild carrot family (also known as Umbelliferae or Apiaceae), which include dill, fennel, tansy, Queen Anne's lace, caraway, coriander, and parsnip. They have small, open flowers that are accessible to the tiny mouthparts of small, parasitic wasps. Fennel is attractive to small parasitic wasps and its flowers are also attractive to syrphid flies, lacewings, mantids, lampyrids (lightning bugs) and ladybugs [42]. [43] reported that, coriander and buckwheat increased the longevity of a parasitoid Dolichogenidea tasmanica (Braconidae). The plants can be incorporated in bean fields. Coriander could also attract adult lacewing (Chrysoperla externa). Adult lacewing can also be attracted by infested rose [44]. [45] reported that sweet alyssum attracted a large number of adult hoverflies.

Despite their effectiveness in biological control, the potential of cover plants in IPM has not been fully explored. Thus, detailed knowledge of the way the cover plants affect the natural enemies and pollinators in cropping systems is essential for sustainable control of insect pests especially in bean fields.

\subsection{Banker Plants}

Banker plants are normally employed to control pests. A study by [46] showed that banker plants are infested with herbivores that serve as alternate hosts or prey for a specific parasitoid or predator but do not cause damage to the crop intended for harvesting. Having a crape myrtle plant (Lagerstroemia indica) in the bean field will attract crape myrtle aphids (Tinocallis kahawaluokalani) to the plant and in turn, beneficial insects which are parasitoids or predators of aphids such as lady beetles will come to the plant and destroy them. More knowledge is needed to provide an understanding of the different banker plants that can be incorporated in bean fields. Such knowledge is essential in improving the efficiency of beneficial arthropods' activities.

\subsection{Field Protection}

[47] reported that excessive wind prevented foraging by adult hoverflies. Thus, protection of natural enemies and pollinators in bean fields can be provided by hedgerows, windbreaks, or shelter-belts which can also serve as shelters to field crops leading to locally elevated temperatures in the sheltered areas. [48] reported that, hedgerows could also serve as alternative habitat for natural enemies. Including non-crop plants in agricultural fields such as bean fields can also help to moderate environmental conditions such as temperature and humidity [8]. Other studies have indicated limited importance of establishing field protection in agricultural fields especially in bean fields. It is therefore of utmost importance to investigate the potential of field protection practices and the ways beneficial arthropods benefit from them.

\section{Research Needs and Conclusions}

Natural enemies and pollinators in bean fields play an important role in increasing bean productivity. Proper identification and understanding of natural enemies, as well as pollinators, is the first step in implementing biological control and enhancing pollination activity. It is important to realize the key benefits of ecosystem services. Much of sub-Saharan Africa has a limited understanding of the pollination and natural pest management services provided by invertebrate populations in and around agricultural fields. Natural enemies and pollinators need overwintering sites, floral resources, protection from heat and desiccation and food prey. Providing favourable environment would help to maintain the beneficial insects throughout their life cycles. Different Integrated Pest Management (IPM) strategies which are environmental benign should be employed. Avoiding indiscriminate use of chemical pesticides and switching to the use of botanicals is one of the beneficial practices that 
can be incorporated in bean fields for conservation of natural enemies and pollinators. It is important to identify and determine the abundance of beneficial insects in bean fields as the important agents in the provision of the needed ecosystem services for bean production.

\section{References}

[1] Millennium Ecosystem Assessment (MEA) (2005) Ecosystems and Human Well-Being: Wetlands and Water. World Resources Institute, Washington DC.

[2] Lead, C., Kumar, P., Brondizio, E., Elmqvist, T., Gatzweiler, F., Gowdy, J. and Reyers, B. (2009) The Economics of Ecosystems and Biodiversity: The Ecological and Economic Foundation. Earthscan, London and Washington DC.

[3] Pascal, U., Muradian, R., Brander, L., Gomez-Baggethun, E., Martin-Lopez, B., Berma, M. and Christie, M. (2010) TEEB Chapter 5 The Economics of Valuing Ecosystem Services and Biodiversity. In: Kumar, P., Ed., The Economics of Ecosystems and Biodiversity: The Ecological and Economic Foundations, Earthscan, London, 183-256

[4] Gurr, G.M. and Kvedaras, O. (2010) Synergizing Biological Control: Scope for Sterile Insect Technique, Induced Plant Defences and Cultural Techniques to Enhance Natural Enemy Impact. Biological Control, 52, 198-207. http://dx.doi.org/10.1016/j.biocontrol.2009.02.013

[5] Lee, J.C.T. and Landis, D.A. (2001) Natural Enemies in Field Crops: A Guide to Biological Control. Michigan State University Extension, East Lansing.

[6] Cork, A., Dobson, H., Grzywacz, D., Hodges, R., Orr, A. and Stevenson, P. (2009) Review of Pre- and Post-Harvest Pest Management for Pulses with Special Reference to East and Southern Africa. Natural Resources Institute, University of Greenwich, London.

[7] Irtwange, S. (2006) Application of Biological Control Agents in Pre- and Post-Harvest Operations. Agricultural Engineering International: The CIGR Ejournal, 8, 1-10.

[8] Mahr, D.L., Ridgway, N.M. and Whitaker, P. (2008) Biological Control of Insects and mites: An Introduction to Beneficial Natural Enemies and Their Use in Pest Management. Extension Biological Control Programs, University of Wisconsin, Madison.

[9] SCLT (2009) The Bug Book: A Garden Field Guide. Southside Community Land Trust, Providence.

[10] Brun, C.A. (2014) Beneficial Insects, Spiders, and Other Mini-Creatures in Your Garden: Who They Are and How to Get Them to Stay. Washington State University Extension, USA.

[11] New, T.R., McEwen, P.K. and Whittington, A.E. (2001) Lacewings in the Crop Environment. Cambridge University Press, Cambridge.

[12] Chin, D. and Brown, H. (2010) Biological Control: With Natural Enemies in the Top End. Department of Resources, Darwin.

[13] Belmain, S., Haggar, J., Holt, J. and Stevenson, P. (2013) Managing Legume Pests in Sub-Saharan Africa: Challenges and Prospects for Improving Food Security and Nutrition through Agro-Ecological Intensification.

[14] Macfadyen, S., Davies, A.P. and Zalucki, M.P. (2015) Assessing the Impact of Arthropod Natural Enemies on Crop Pests at the Field Scale. Insect Science, 22, 20-34. http://dx.doi.org/10.1111/1744-7917.12174

[15] Nicholls, C.I. and Altieri, M.A. (2013) Plant Biodiversity Enhances Bees and Other Insect Pollinators in Agroecosystems. A Review. Agronomy for Sustainable Development, 33, 257-274. http://dx.doi.org/10.1007/s13593-012-0092-y

[16] Rondon, S.I., Clough, G.H. and Corp, M.K. (2008) How to Identify, Scout, and Control Insect Pests in Vegetable Crops. Oregon State University, Extension Service, Corvallis.

[17] Javahery, M. (2013) Natural History of Reduvius personatus Linnaeus (Hemiptera: Heteroptera: Reduviidae) in North America. Munis Entomology \& Zoology, 8, 685-703.

[18] Stewart, S.D., Layton, B. and Catchot, A. (2007) Common Beneficial Arthropods Found in Field Crops. University of Tennessee Extension, Knoxville. http://msucares.com/pubs/publications/e0020.pdf

[19] Cooperative Extension Service (CES) (2010) Insects and Spiders of Alaska. University of Alaska, Fairbanks.

[20] Alston, D. (2011) Attracting and Supporting Beneficial Insects in the Landscape. Utah State University Cooperative Extension, Wellsville.

[21] Cunningham, A.P., Brandle, J.R., Danielson, S.D. and Hunt, T.E. (2007) Lady Beetles of Nebraska. Nebraska University of Lincoln Extension, Lincoln.

[22] Getanjaly, V.L.R., Sharma, P. and Kushwaha, R. (2015) Beneficial Insects and Their Value to Agriculture. Research Journal of Agriculture and Forestry Sciences, 3, 25-30.

[23] AHDB (2014) Encyclopedia of Pests and Diseases. Agriculture and Horticulture Development Board, Kenilworth. 
[24] Pesticide Action Network (PAN) (2014) Field Guide to Non Chemical Pest Management in Cowpea Production. PAN, Hamburg.

[25] Bessin, R. and Obrycki, J. (2011) An IPM Scouting Guide for Natural Enemies of Vegetable Pests. University of Kentucky College of Agriculture, Cooperative Extension Service, Lexington.

[26] Brier, H., Wessels, J. and Charleston, K. (2012) Good Bug? Bad Bug? An Identification Guide for Pest and Beneficial Insects in Summer Pulses, Soybeans, Peanuts and Chickpeas.

[27] Fernandes, F.L., Bacci, L. and Fernandes, M.S. (2010) Impact and Selectivity of Insecticides to Predators and Parasitoids. EntomoBrasilis, 3, 1-10. http://dx.doi.org/10.12741/ebrasilis.v3i1.52

[28] Elmqvist, T., Maltby, E., Barker, T., Mortimer, M., Perrings, C., Aronson, J. and Norberg, J. (2010) Biodiversity, Ecosystems and Ecosystem Services. In: Kumar, P., Ed., The Economics of Ecosystems and Biodiversity: The Ecological and Economic Foundations, Earthscan, London, 41-111.

[29] Altieri, M.A., Nicholls, C.I., Gillespie, M., Waterhouse, B., Wratten, S., Gbèhounou, G. and Gemmill-Herren, B. (2015) Crops, Weeds and Pollinators Understanding Ecological Interaction for Better Management.

[30] United States Department of Agriculture (USDA) (2013) Types of Pollinators. Utah State University Cooperative Extension, Logan.

[31] Hopwood, J. (2010) Pollinators and Roadsides: Managing Roadsides for Bees and Butterflies.

[32] Blaauw, B.R. and Isaacs, R. (2014) Flower Plantings Increase Wild Bee Abundance and the Pollination Services Provided to a Pollination-Dependent Crop. Journal of Applied Ecology, 51, 890-898. http://dx.doi.org/10.1111/1365-2664.12257

[33] Martins, D.J. (2014) Our Friends the Pollinators: A Handbook of Pollinator Diversity and Conservation in East Africa. Nature Kenya, Nairobi.

[34] Letourneau, D. and Altieri, M. (1999) Environmental Management to Enhance Biological Control in Agroecosystems. In: Bellows, T.S., Fisher, T.W., Caltagirone, L.E., Dahlsten, D.L., Gordh, G. and Huffaker, C.B., Eds., Handbook of Biological Control, Academic Press, San Diego, 319-354. http://dx.doi.org/10.1016/B978-012257305-7/50061-8

[35] Gurr, G.M., Wratten, S.D. and Altieri, M.A. (2004) Ecological Engineering for Pest Management: Advances in Habitat Manipulation for Arthropods. Csiro Publishing, Clayton.

[36] Kasina, J., Nderitu, J., Nyamasyo, G., Olubayo, F., Waturu, C., Obudho, E. and Yobera, D. (2006) Evaluation of Companion Crops for Thrips (Thysanoptera: Thripidae) Management on French Bean Phaseolus vulgaris (Fabaceae). International Journal of Tropical Insect Science, 26, 121-125. http://dx.doi.org/10.1079/IJT2006105

[37] Otieno, M., Woodcock, B.A., Wilby, A., Vogiatzakis, I.N., Mauchline, A.L., Gikungu, M.W. and Potts, S.G. (2011) Local Management and Landscape Drivers of Pollination and Biological Control Services in a Kenyan Agro-Ecosystem. Biological Conservation, 144, 2424-2431. http://dx.doi.org/10.1016/j.biocon.2011.06.013

[38] Pickett, C.H. (1998) Enhancing Biological Control: Habitat Management to Promote Natural Enemies of Agricultural Pests. University of California Press, Oakland.

[39] Sigsgaard, L., Betzer, C., Naulin, C., Eilenberg, J., Enkegaard, A. and Kristensen, K. (2013) The Effect of Floral Resources on Parasitoid and Host Longevity: Prospects for Conservation Biological Control in Strawberries. Journal of Insect Science, 13, 104. http://dx.doi.org/10.1673/031.013.10401

[40] Schmidt, M.H. and Tscharntke, T. (2005) The Role of Perennial Habitats for Central European Farmland Spiders. Agriculture, Ecosystems \& Environment, 105, 235-242. http://dx.doi.org/10.1016/j.agee.2004.03.009

[41] Ricketts, T.H., Daily, G.C., Ehrlich, P.R. and Michener, C.D. (2004) Economic Value of Tropical Forest to Coffee Production. Proceedings of the National Academy of Sciences of the United States of America, 101, 12579-12582. http://dx.doi.org/10.1073/pnas.0405147101

[42] Zehnder, G. (2013) Farmscaping: Making Use of Nature’s Pest Management Services. Clemson University, Clemson.

[43] Irvin, N., Wratten, S., Chapman, R. and Frampton, C. (1999) Effects of Floral Resources on Fitness of the Leafroller Parasitoid (Dolichogenidea tasmanica) in Apples. Proceedings of the New Zealand Plant Protection Conference, 52, 84-88.

[44] Salamanca, J., Pareja, M., Rodriguez-Saona, C., Resende, A. and Souza, B. (2015) Behavioral Responses of Adult Lacewings, Chrysoperla externa, to a Rose-Aphid-Coriander Complex. Biological Control, 80, 103-112. http://dx.doi.org/10.1016/j.biocontrol.2014.10.003

[45] Hogg, B.N., Bugg, R.L. and Daane, K.M. (2011) Attractiveness of Common Insectary and Harvestable Floral Resources to Beneficial Insects. Biological Control, 56, 76-84. http://dx.doi.org/10.1016/j.biocontrol.2010.09.007

[46] Knox, G.W. (2000) Crape myrtle in Florida.

[47] Bugg, R.L. and Waddington, C. (1994) Using Cover Crops to Manage Arthropod Pests of Orchards: A Review. Agri- 
culture, Ecosystems \& Environment, 50, 11-28. http://dx.doi.org/10.1016/0167-8809(94)90121-X

[48] Thomas, M., Wratten, S. and Sotherton, N. (1991) Creation of “Island” Habitats in Farmland to Manipulate Populations of Beneficial Arthropods: Predator Densities and Emigration. Journal of Applied Ecology, 28, 906-917. http://dx.doi.org/10.2307/2404216 